\title{
Implications for breast cancer dormancy in other areas of medicine
}

\author{
This article was published in the following Dove Press journal: \\ Breast Cancer:Targets and Therapy \\ 4 December 2012 \\ Number of times this article has been viewed
}

\section{Pranela Rameshwar}

New Jersey Medical School, University of Medicine and Dentistry of New Jersey, Newark, NJ, USA
Correspondence: Pranela Rameshwar UMDNJ-New Jersey Medical School,

185 South Orange Avenue, MSB E-585, Newark, NJ, USA 07I03

Tel +l 9739720625

Fax + I 9739728854

Email rameshwa@umdnj.edu
Banys et al ${ }^{1}$ discussed the different viewpoints of breast cancer dormancy; albeit those that are supported by science. This editorial comments on the clinical implications of existing dormant cancer cells, including future decisions to treat with stem cells.

Braun et $\mathrm{al}^{2}$ reported that in cases where metastasis of breast cancer occurred in the bone marrow, this resulted in poor prognosis. As discussed by the authors, it is unclear whether breast cancer cells show tropism for an organ, or whether the cells are able to survive in a particular organ because of support from the microenvironment. Perhaps answers to this question might be clearer if a hierarchy of breast cancer cells is developed, beginning with the cancer stem cell. Depending on the cell subset, there might be a different mechanism for dormancy in an organ.

The authors discussed two broad methods of dormancy, one in which the cells changed the pattern of cell cycle, and the other, in which the micrometastasis was caused by a balance between cancer cell proliferation and cell death. Each broad view is likely to have many different subdivisions to explain dormancy. For example, the changes in cytokine production by the cancer cells within a distant site could be responsible for the change in cell cycle of the breast cancer cells. In other mechanisms, gap junctional intercellular communication can be established with the stromal cells within the microenvironment. ${ }^{3}$

Banys et al ${ }^{1}$ discussed the premetastatic niche caused by fibronectin for the recruitment of bone marrow cells. The occurrence of such a mechanism may provide insights into the reason for breast cancer to be attracted to the bone marrow and in particular, close to the endosteum, where the hematopoietic stromal cells produce extracellular matrix, such as fibronectin. In bone marrow, the supporting cells are already present. This might partly explain why the bone marrow attracts breast cancer cells, and facilitates the cells' existence. The existence of the cancer cells among extracellular matrices such as fibronectin within the hematopoietic niche, raises an important argument about whether bone invasion is an opportunistic process. Specifically, if premetastatic sites can be established by fibronectin for the attraction of bone marrow cells, this argues in favor of the environment as a preference for dormancy, rather than the organ. This will then support the microenvironment rather than the organ, as the limiting milieu for dormancy. Although Banys et al ${ }^{1}$ discussed the mutual relationship between the two methods of dormancy, it is possible that the mechanisms of dormancy might be exclusive, and that each will depend on the subset of cancer 
cells with distinct interactions with cells and factors within the microenvironment.

A comment is required on the section regarding circulating tumor cells. ${ }^{1}$ The review discussed the different findings regarding the circulating tumor cells. The persistent argument for the benefit of removing lymph nodes in breast cancer patients is inclusive of the function of circulating tumor cells. ${ }^{4}$ The experimental and clinical evidence support a subset of stem cells in breast and other cancers. The authors stated $0.01 \%$ of circulating breast cancer cells can produce a single tumor metastasis. This relatively small subset of tumor initiated breast cancer cells is consistent with the low percentages of a stem cell subset reported in tumors. Future challenges include studies that determine whether the subset of circulating tumor cells that form metastasis show properties of stem cells and also, whether these cells resist current treatments. If so, this subset of cell will need to be characterized because this may hold the key to the development of new forms of treatments. It is also important to note whether the circulating cancer cells bypass the lymph nodes. This information would add to ongoing studies to understand how an individual can exist for decades with dormant breast cancer cells.

\section{Implications for stem cell therapy}

The review on cancer dormancy, by Banys et al ${ }^{1}$ brings up a timely question about the implication for stem cell therapy. The question is whether stem cell treatment should be designed with strategies to retain the dormant cancer cells in their quiescent phase, or to treat the cancer if the stem cell treatment induced tumor growth and metastasis. Indeed, at least for mesenchymal stem cells (MSCs), their "attractiveness" as an off-the-shelf source for cell therapy could be confounded by their ability to support tumor growth, breast cancer included. ${ }^{5,6}$ The inclusion criteria for treating patients with stem cells will have to incorporate questions about the patient's history of cancer.

Another implication for dormant cancer cells is the potential confounding of drug delivery by stem cells such as MSCs. ${ }^{7}$ This indication is based on the ability of MSCs to home towards tumors, which makes MSCs attractive to deliver drugs to tumors. However, the supporting role for MSCs in tumor growth and progression leaves questions about the ability of MSCs to be ideal for the cellular delivery of drugs. ${ }^{5,8}$

In an ideal scenario, if a hierarchy of cancer cell subsets is established and the cancer stem cells are characterized, it will be a challenge to target the stem cell population because this could be toxic to the normal stem cells in the various organs. As discussed by Banys et al, ${ }^{1}$ the subject of dormancy is still an open field for investigation. The mechanism of dormancy, combined with the identification of the candidate subset, will lead to the development of strategies to reverse dormancy for drug targeting.

\section{Acknowledgment}

This work was supported by the Department of Defense.

\section{Disclosure}

The author declares no conflicts of interest in this work.

\section{References}

1. Banys M, Hartkop AD, Krawczyk N, et al. Dormancy in breast cancer. Breast Cancer: Targets Ther. 2012;4:183-191.

2. Braun S, Auer D, Marth C. The prognostic impact of bone marrow micrometastases in women with breast cancer. Cancer Invest. 2009; 27(6):598-603.

3. Lim PK, Bliss SA, Patel SA, et al. Gap junction-mediated import of microRNA from bone marrow stromal cells can elicit cell cycle quiescence in breast cancer cells. Cancer Res. 2011;71(5):1550-1560.

4. Kawada K, Taketo MM. Significance and mechanism of lymph node metastasis in cancer progression. Cancer Res. 2011;71(4):1214-1218.

5. Greco SJ, Patel SA, Bryan M, Pliner LF, Banerjee D, Rameshwar P. AMD3100-mediated production of interleukin-1 from mesenchymal stem cells is key to chemosensitivity of breast cancer cells. Am J Cancer Res. 2011;1(6):701-715.

6. Patel SA, Meyer JR, Greco SJ, Corcoran KE, Bryan M, Rameshwar P. Mesenchymal stem cells protect breast cancer cells through regulatory T cells: role of mesenchymal stem cell-derived TGF-beta. $J$ Immunol. 2010;184(10):5885-5894.

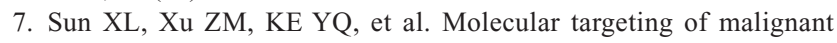
glioma cells with an EphA2-specific immunotoxin delivered by human bone marrow-derived mesenchymal stem cells. Cancer Lett. 2011;312(2):168-177.

8. Grisendi G, Bussolari R, Veronesi E, et al. Understanding tumor-stroma interplays for targeted therapies by armed mesenchymal stromal progenitors: the Mesenkillers. Am J Cancer Res. 2011;1(6):787-805. 


\section{Publish your work in this journal}

Breast Cancer: Targets and Therapy is an international, peer- View the full aims and scopes of this journal here. The manuscript reviewed open access journal focusing on breast cancer research, management system is completely online and includes a very quick identification of therapeutic targets and the optimal use of preven- and fair peer-review system, which is all easy to use. Visit http:// tative and integrated treatment interventions to achieve improved www.dovepress.com/testimonials.php to read real quotes from outcomes, enhanced survival and quality of life for the cancer patient. published authors.

Submit your manuscript here: http://www.dovepress.com/breast-cancer---targets-and-therapy-journal 